\title{
EDUCAÇÃO MUSICAL ESCOLAR EM PORTUGAL: A DISCIPLINA CANTO CORAL NA PRIMEIRA REPÚBLICA (I9IO-I926)
}

\section{Educación musical escolar en Portugal: la disciplina Canto Coral en la Primera República (I9I0-I926)}

\section{School musical education in Portugal: the subject of Choral Singing in the First Republic (1910-1926)}

\author{
Elias Souza Dos Santos ${ }^{1}$ \\ Universidade Tiradentes \\ Correo-e: essregentedecorais@gmail.com \\ Margarida Louro Felgueiras \\ Universidade do Porto \\ Correo-e: margalf@gmail.com \\ Cristiano FERronato \\ Universidade Tiradentes \\ Correo-e: cristianoferronato@gmail.com
}

Recepción: 20 de diciembre de 20I9. Envío a informantes: 22 de diciembre de 2019 Aceptación definitiva: 6 de abril de 2020

Resumo: Este trabalho tem como propósito analisar o modo pelo qual a disciplina Canto Coral se configurou no currículo da escola portuguesa, durante o regime da Primeira República. Trata-se de uma pesquisa bibliográfica, respaldada nos pressupostos teóricos da Cultura Escolar. Foi através do Decreto n. ${ }^{\circ} 4650$, de 14 de julho

1 Doutorando em Educação pelo Programa de Pós-Graduação em Educação da Universidade Tiradentes. A piori, esta pesquisa recebeu o apoio da Ford Foundation Education Institute. O trabalho foi apresentado, pela primeira vez, em 20Io, no Congresso Nacional A I República e a Educação, na cidade Joane, Vila Nova de Famalicão, em Portugal. Atualmente, esta investigação tem recebido o financiamento da Coordenação de Aperfeiçoamento de Pessoal de Nível Superior (CAPES) e do Programa de Suporte à Pós-Graduação de Instituições de Ensino Particulares (PROSUP), do Ministério da Educação do Brasil. 


\section{EDUCAÇÃO MUSICAL ESCOLAR EM PORTUGAL: \\ 358 A DISCIPLINA CANTO CORAL NA PRIMEIRA REPÚBLICA (I9I0-I926) \\ ELIAS SOUZA DOS SANTOS ; MARGARIDA LOURO FELGUEIRAS Y CRISTIANO FERRONATO}

de 1918, que a disciplina Canto Coral passou a fazer parte do currículo dos Liceus. O objetivo era contribuir para a educação da voz, do sentimento estético e, especialmente, para o desenvolvimento do nacionalismo. O mesmo Decreto que criou a disciplina Canto Coral estabelecia, também, a criação de um Orfeão nos estabelecimentos de ensino. Os Orfeões se tornaram veículos de difusão das ideias republicanas. Sua função primeira, não era atribuir um papel educativo à disciplina Canto Coral, na formação dos escolares, mas, propagar a ideologia do governo vigente.

Palavras-chave: disciplina escolar; manual pedagógico; Canto Coral; Primeira República; Portugal.

Resumen: Se trata de una investigación bibliográfica, respaldada en los presupuestos teóricos de la Cultura Escolar. Fue a través del Decreto n. ${ }^{\circ} 650$, de i4 de julio de I9ı8, que la disciplina Canto Coral pasó a formar parte del currículo de los Liceos. El objetivo era contribuir a la educación de la voz, del sentimiento estético y, especialmente, al desarrollo del nacionalismo. El mismo decreto que creó la disciplina Canto Coral establecía, también, la creación de un orfeón en los establecimientos de enseñanza. Los orfeones se convirtieron en vehículos de difusión de las ideas republicanas. Su función primera no era atribuir un papel educativo a la disciplina Canto Coral, en la formación de los escolares, sino propagar la ideología del Gobierno vigente.

Palabras clave: disciplina escolar; manual pedagógico; Canto Coral; Primera República; Portugal.

AвsтRAct: This research has the aim of analyzing the way of which the subject of Choral Singing was configured on the curriculum of the Portuguese school, during the First Republic. It is a bibliographic research endorsed on the theoretical premise of Scholar Culture. It was through the Decree No. 4650, of I4 July I9I8, that the subject of Choral Singing started to be a part of the Lyceum. The goal was to contribute to the education of the voice, the aesthetic feeling and, mainly, the development of nationalism. The same Decree that originated the subject of Choral Singing also established the creation of an Orfeão in the educational institutes. The Orfeões became ways of diffusion of republican ideas. Its purpose was not to attribute an educative role to the subject of Choral Singing on the shaping of the mentees, but to spread the ideology of the current government.

KEY wORDs: school subject; pedagogical manual; Choral Singing; First Republic; Portugal.

\section{Introdução}

$\mathrm{E}$ STE TRABalho TEM COMo pRopósito analisar o modo pelo qual a disciplina Canto Coral se configurou na escola portuguesa, durante a Primeira República, tendo em conta o início de suas práticas, seus objetivos e a sua funcionalidade. Trata-se de uma pesquisa bibliográfica, que toma como respaldo 
EDUCAÇÃO MUSICAL ESCOLAR EM PORTUGAL:

A DISCIPLINA CANTO CORAL NA PRIMEIRA REPÚBLICA (I9IO-I926)

ELIAS SOUZA DOS SANTOS ; MARGARIDA LOURO FELGUEIRAS Y CRISTIANO FERRONATO

teórico-metodológico as abordagens desenvolvidas por Goodson ${ }^{2}, \mathrm{Julia}^{3}$, Chervel $^{4}$, Bittencourt ${ }^{5}$, Fernández $^{6}$, Artiaga ${ }^{7}$, Viana $^{8}$, Brito e Cymbron ${ }^{9}$, Pintassilgo ${ }^{10}$, Ramos do $\mathrm{O}^{11}$. O objetivo central é estudar a forma pela qual a disciplina Canto Coral se constituiu no currículo da escola portuguesa da Primeira República. Todavia, recuou-se para o final da segunda metade do século xIx, uma vez que ela já havia sido inserida no currículo da escola primária.

Antes de abordarmos o surgimento da disciplina Canto Coral, convém discutir com os estudiosos que já vêm desenvolvendo pesquisas sobre a cultura escolar, da qual a disciplina escolar faz parte. Tal como André Chervel (I990, p. I80), para nós «uma 'disciplina' é, qualquer que seja o campo do saber a que pertença, um modo de disciplinar o espírito, quer dizer de lhe dar os métodos e as regras para abordar os diferentes domínios do pensamento, do conhecimento e da arte».

Para Chervel, o termo «disciplina escolar» refere-se ao ensino básico e, disciplina acadêmica, diz respeito àquelas estudadas na universidade. $\mathrm{Na}$ concepção de Goodson, a ideia de que as disciplinas são originadas na academia para depois ser transportada ao contexto escolar é descartada. Mesmo assim, o autor afirma que as disciplinas escolares recebem influências de intelectuais formados na academia, mas, nem por isso, elas são originadas na academia, nem tampouco transportada. Posição um pouco diferente da anteriormente assumida pelos sociólogos, didáticos e filósofos da educação, ingleses como Hirst e Peters ${ }^{12}$, para quem a disciplina é criada por intelectuais no interior de uma universidade para, em seguida, ser traduzida como matéria escolar, fazem uso do termo «transposição didática», porque defendem a tese de que é o saber científico que legitima

2 Goodson, I.: «Tornando-se uma matéria acadêmica: padrões de explicação e evolução», Teoria E Educação, Porto Alegre, n. 2 (1990), pp. 230-245.

3 Julia, D.: «A cultura escolar como objeto histórico», Revista Brasileira de História da Educação, Campinas, Editora Autores Associados, n. ${ }^{\circ}$ I (Jan./Jun., 20oI), pp. 9-43.

4 Chervel, A.: «História das disciplinas escolares: reflexões sobre um campo de pesquisa», Teoria E Educação, Porto Alegre, n. 2 (1990), pp. 177-229.

BitTencourt, C. M. F.: «Disciplinas escolares: história e pesquisa», in Oliveira, M. A. T. e Ranzi, S. M. F. (orgs.): História das disciplinas escolares no Brasil: contribuições para o debate, Bragança Paulista, EDUSF, 2003, pp. 9-38.

6 Fernández, R. C.: Sociogénesis de uma disciplina escolar: lá historia, Barcelona, Edicon originale em Pomares-Corredor, 1997. Verson eletrônica, 2009, http://www.historialudens.it/images/ download/sociogenesisd eunadiscplinaes colar.pdf.

Artiaga, M. J.: «A disciplina de Canto Coral e o seu Repertório de r9i8 a I960», Revista Música, Psicologia e Educação, Centro de Investigação em Psicologia da Música e Educação MusicalCIPEM, Porto, Escola Superior de Educação do Porto (200I).

8 Viana, L.: A mocidade portuguesa: lá vamos cantando... (1936-1974), Lisboa, Educa, 2001.

9 Brito, M. C. e Cymbron, L.: História da música portuguesa, Lisboa, Universidade Aberta, I992.

Io Pintassilgo, J.: A República e a Educação: dos projectos às realizações Biblioteca da Faculdade de Lisboa, 20II, https://repositorio.ul.pt/handle/1045I/7792.

"I Ramos do Ó, J. R.: O ensino liceal (1836-1975), 2009, https://repositorio.ul.pt/bitstream/ro451/6296/I/Ensino \% 20Liceal\% 20.pdf.

${ }_{12}$ Hirst, P. H. e Peters, R. S.: A Lógica da Educação, tradução da I. a ed., 1970, Rio de Janeiro, Zahar Editores, 1972, pp. 85-98. 
EDUCAÇÃO MUSICAL ESCOLAR EM PORTUGAL:

360

A DISCIPLINA CANTO CORAL NA PRIMEIRA REPÚBLICA (I9IO-I926)

ELIAS SOUZA DOS SANTOS ; MARGARIDA LOURO FELGUEIRAS Y CRISTIANO FERRONATO

as disciplinas escolares; por isso, afirmam que as disciplinas são originadas no ambiente acadêmico, e, posteriormente, transportadas para o contexto da escola.

$\mathrm{Na}$ visão de Raimundo Fernández, quando se pretende estudar a psicogênese de uma disciplina escolar, é importante adotar a categoria de análise "código disciplinar», tendo em vista que, [...] «las disciplinas escolares son construcciones históricas socialmente condicionadas y gestadas dentro de instituciones específicas de socialización» ${ }^{13}$. Para o mencionado autor, o código disciplinar pode ser entendido como uma tradição, formatada «históricamente y compuesta de un conjunto de ideas, valores, suposiciones y rutinas, que legitiman la función educativa atribuída» ${ }^{14}$. Uma vez que integra discurso, conteúdo e prática que interagem e se transformam, a depender dos usos adotados pelas instituições educativas, o código disciplinar, enquanto categoria, pode ser adotado, também, para examinarmos a disciplina "Canto Coral» na escola da I República de Portugal.

Segundo Bittencourt ${ }^{15}$, os conceitos de disciplina escolar defendidos por Ivor Goodson e Chervel, embora com pequenas diferenças, assemelham-se. Por outro lado, Chevallard, Hirst e Peters partem do ambiente universitário para a compreensão do currículo escolar. Após colocar-nos frente à discussão teórica, a autora opta pelo conceito defendido por Chervel. Segundo este autor, a história das disciplinas escolares deve ser investigada, levando em consideração três aspectos: sua gênese, seus objetivos e o seu funcionamento. Além do mais, as disciplinas escolares se constituem em campos epistemológicos autônomos, uma vez que são originadas no interior da cultura escolar. Portanto, para sua constituição elas não dependem do auxílio dos conhecimentos produzidos na universidade.

O texto de Circe Bittencourt, ao fazer o ponto da situação do desenvolvimento do debate e das tendências atuais que estruturam o campo das pesquisas sobre as disciplinas escolares, é essencialmente útil para os estudos em história da educação e constitui uma referência para os pesquisadores que pretendem realizar suas primeiras incursões nesta área. Acresce que a autora, ao tempo em que utiliza uma linguagem academicamente técnica, também conduz o leitor a uma fácil compreensão do objeto, levando-o a conceber o momento inicial do desenvolvimento das disciplinas que estruturam a educação básica e secundária.

Vale também atentarmos para os esclarecimentos que Dominique Julia nos dá sobre as disciplinas escolares. Segundo o autor:

a história das disciplinas escolares [...] tenta identificar, tanto através das práticas de ensino utilizadas na sala de aula como através dos grandes objetivos que presidiram a constituição das disciplinas, o núcleo duro que pode constituir uma história renovada da educação. Ela abre, em todo caso, para retomar uma metáfora

13 Fernández, R. C.: Sociogénesis de uma disciplina escolar: lá historia, Barcelona, Edicon originale em Pomares-Corredor, I997. Verson eletrônica, 2009, p. 7, http:// www. historialudens. it/ images/ download/ sociogenesisdeunadiscplinaes colar.pdf.

${ }_{14}$ Ibid., p. 8.

is Bittencourt, C. M. F.: «Disciplinas escolares: história e pesquisa», in Oliveira, M. A. T. e Ranzi, S. M. F. (orgs.): História das disciplinas escolares no Brasil: contribuições para o debate, Bragança Paulista, EDUSF, 2003, pp. 9-38. 
EDUCAÇÃO MUSICAL ESCOLAR EM PORTUGAL:

A DISCIPLINA CANTO CORAL NA PRIMEIRA REPÚBLICA (I9IO-I926)

ELIAS SOUZA DOS SANTOS ; MARGARIDA LOURO FELGUEIRAS Y CRISTIANO FERRONATO

aeronáutica, a «caixa preta» da escola, ao buscar compreender o que ocorre nesse espaço particular ${ }^{16}$.

Nas duas últimas décadas, os estudos das práticas escolares avançou de forma significativa e têm contribuído para uma nova compreensão do ambiente escolar. Para Bittencourt

esta linha de pesquisa tem contribuído para o desenvolvimento de análises educacionais visando situar o conjunto de agentes constituintes do saber escolar, especialmente professores, alunos e comunidade escolar, e nesse processo, as disciplinas escolares passaram a ser incluídas como um dos objetos importantes das investigações sobre as práticas escolares ${ }^{17}$.

A autora comenta ainda que algumas disciplinas, em outras épocas, fizeram parte do currículo da escola e tiveram sua importância, a exemplo do Latim e Moral e Cívica. Vale ressaltar que a disciplina Canto Coral passou a fazer parte do currículo da escola portuguesa primária no final da segunda metade do século XIx.

\section{A gênese do Orfeão}

A prática do canto individual ou coletivo não é uma novidade das sociedades modernas. Presente em todos os povos, dos mais primitivos aos mais «civilizados», a música vocal manifestou-se de diversas formas e com várias finalidades. Ora conectada com a dança, ora separada, em alguns períodos históricos exprimiu-se nas práticas religiosas e cívicas, como recurso de memorização nas escolas de profetas de Israel, na educação de crianças e jovens, na política, nas guerras, nos banquetes e nas festas.

No final da primeira década do século XIX, o pedagogo e compositor suíço Hans Georg Nageli (I773-I836), conhecido como o pai dos coros masculinos, iniciou um trabalho de canto coletivo e fundou o Instituto de Canto de Zurique, em i805. Nessa instituição Nageli dirigiu um coro misto, um coro de pequenos cantores e um coro masculino. Anos depois (I824) o compositor fundou duas sociedades: a Sociedade Coral de Zurique e a Sociedade Musical Feminina. Até I834 existiam na Suíça, sem contar com os escolares, mais de vinte mil cantores que integravam os grupos corais desse país ${ }^{18}$. Seguindo o exemplo da Suíça, o movimento associativo do canto coral se disseminou para outros países da Europa, a

${ }^{16}$ Julia, D.: «A cultura escolar como objeto histórico», Revista Brasileira de História da Educação, Campinas, Editora Autores Associados, n. ${ }^{\circ}$ I (Jan./Jun., 200I), p. I3.

${ }_{17}$ Bittencourt, C. M. F.: «Disciplinas escolares: história e pesquisa», in Oliveira, M. A. T. e Ranzi, S. M. F. (orgs.): História das disciplinas escolares no Brasil: contribuições para o debate, Bragança Paulista, EDUSF, 2003, p. I3.

I8 Bonito, R.: Canto coral e vida orfeônica: subsídio para a bistória do canto colectivo popular e artístico, Porto, Alttiormelior, 1952. 
EDUCAÇÃO MUSICAL ESCOLAR EM PORTUGAL:

362

A DISCIPLINA CANTO CORAL NA PRIMEIRA REPÚBLICA (I9IO-I926)

ELIAS SOUZA DOS SANTOS ; MARGARIDA LOURO FELGUEIRAS Y CRISTIANO FERRONATO

exemplo da França, Alemanha, Inglaterra, Portugal e Espanha; e da América, a exemplo dos Estados Unidos, do Brasil e da Argentina, dentre outros ${ }^{19}$.

Até 1832 os grupos que praticavam o canto coletivo denominavam-se corais ${ }^{20}$. A partir de 1833, segundo Yolanda Arruda, o coordenador do ensino de canto das escolas de Paris, Guillaume Louis Bocquillon Wilhem (178I-I842), com o intuito de homenagear o mitológico Orfeu ${ }^{21}$, «adotou o termo L'Orpheon para designar os coros de alunos de todas as escolas, que se reuniam para, de quando em quando, realizar audições» ${ }^{22}$. Desde então, a palavra orfeão passou a ser empregada em vários países, incluindo-se Portugal e Brasil. Cabe destacar que, na França, a música foi introduzida nos currículos da escola politécnica e da escola normal em 1929. Alguns anos depois surgiram as associações orfeônicas, que tinham como objetivo promover a integração social de pessoas de todas as classes sociais e, também, organizar encontros e concursos nacionais e internacionais de orfeões. $\mathrm{Na}$ Alemanha, durante o século xvx, a prática orfeônica ${ }^{23}$ denominou-se Liedertafe $^{24}$ e nele predominou o caráter religioso. Na Inglaterra, Glee ou Madrigal foi o nome dado às sociedades corais que surgiram no século XviII, além das associações denominadas Tonic Sol-Fa Associations. Diferentemente da França, Inglaterra e Alemanha, o orfeonismo na Espanha data de i851 e se destaca pelo caráter de contenção social, ou seja, a priori, foram criados vários orfeões compostos

19 Barreto, C. B.: Coro Orfeão, São Paulo, Companhia Melhoramentos, 1938.

${ }_{20}$ Ibid. O termo côro tem sua origem na palavra grega choros, que significa cortejo dançante, pois antigamente o canto estava atrelado à dança. Com o passar dos anos a palavra côro associou-se ao canto coletivo. Há uma diferença entre as palavras Coral e Orfeão. O termo coral origina-se de coro. O canto coral refere-se à prática de canções de forma coletiva; o termo coral tem a ver com uma forma de composição musical que teve sua origem nos cânticos adotados pela Reforma Protestante, liderada por Lutero. Esse estilo de composição se encontra presente nas obras de J. S. Bach. O coral se diferencia do orfeão porque exige, dos (das) componentes, mais conhecimento da técnica vocal, da partitura, e por executar um repertório mais complexo. Já o orfeão refere-se aos grupos escolares, de associações composta por professores, militares, operários e amadores de música que participavam desses grupos sem nenhum interesse profissional. O repertório interpretado pelos (as) orfeonistas é formado por canções de fácil execução.

${ }_{21}$ Santos, E. S.: Ó tupã deus do Brasil: o canto orfeônico na Escola Normal de Aracaju (19341971), Jundiaí (SP), Paco Editorial, 2016. Orfeu era filho de Apolo, deus da música e do canto, e de Calíope, deusa da poesia épica. Na verdade, em Orfeu é possível perceber o elo entre música e poesia. Reza a lenda que o som da sua lira acalmava os ventos, as tempestades, as plantas e os animais selvagens.

${ }^{22}$ Arruda, Y. Q.: Elementos do canto orfeônico, 34 4d., São Paulo, Companhia Editora Nacional, 1960.

${ }_{23}$ Bonito, R.: Canto coral e vida orfeônica: subsídio para a história do canto colectivo popular $e$ artístico, Porto, Alttiormelior, 1952. Trata-se da prática do canto coletivo executada a uma ou mais vozes, com ou sem acompanhamento de instrumentos musicais. Esse tipo de canto é caracterizado pelo número elevado de cantores, provenientes de várias classes sociais e que se reuniam em sociedades corais.

${ }_{24}$ Gilioli, R. S. P.: "Civilizando» pela música: a pedagogia do canto orfeônico na escola paulista da primeira república (I9Io-I930), São Paulo, Universidade de São Paulo, Faculdade de Educação, 2003. Entende-se por Lieder as canções, os cantos e os hinos; o termo Teafel significa quadro, lousa e letreiro, entre outras. 
EDUCAÇÃO MUSICAL ESCOLAR EM PORTUGAL:

A DISCIPLINA CANTO CORAL NA PRIMEIRA REPÚBLICA (I9IO-I926)

ELIAS SOUZA DOS SANTOS ; MARGARIDA LOURO FELGUEIRAS Y CRISTIANO FERRONATO

pelos operários e, posteriormente, surgiram associações de caráter escolar, acadêmicos, entre outras ${ }^{25}$.

Nos Estados Unidos os orfeões apareceram na segunda metade do século XIX e se desenvolveram por meio das associações denominadas Apollo Clubs, as quais se caracterizaram pela inserção e pela valorização do folclore ${ }^{26}$.

Quanto às práticas orfeônicas no Brasil, assinalamos que esse movimento sofreu influência da França e dos Estados Unidos. Ceição Barreto ${ }^{27}$, Judith Almeida ${ }^{28}$ e Yolanda Arruda ${ }^{29}$, autoras de manuais pedagógicos de Canto Orfeônico, sustentam que as primeiras iniciativas de inserção das práticas orfeônicas nas escolas brasileiras ocorreram no estado de São Paulo, nas duas últimas décadas da Primeira República, e tiveram como mentores João Gomes Junior, Carlos Alberto Gomes Cardim, Lázaro Lozano e João Batista Julião, dentre outros. Porém, pesquisas recentes assinalam que essa prática já existia em outras cidades do Brasil, a exemplo de Belém do Pará. De acordo com Santos, Ferronato e Mecenas ${ }^{30}$, existia, em Belém do Pará, uma prática de educação musical escolar desde 1998, que teve o maestro Clemente Ferreira Júnior, como mentor.

Em Portugal, a terminologia Orpheons aplicou-se aos corais mistos, quer de origem popular quer pertencentes a liceus, escolas e universidades. A presença do movimento orfeônico nesse país iniciou-se com a criação das associações orfeônicas e esteve presente no currículo da escola, através da disciplina Canto Coral. Há registros de inúmeros orfeões criados nas cidades portuguesas e podem ser tomados como exemplos, o Orfeão Acadêmico de Coimbra e o Orfeão do Porto. O primeiro foi fundado em 29 de outubro de 1880 (O Orfeon, 1938); o segundo surgiu em 3 de fevereiro de I9ıo, no Porto (O Orfeão do Porto, 1942). Ambos se tornaram referência nacional e internacional. Vale ressaltar que o Orfeão do Porto completou, em 3 de fevereiro de 2020 , IIo anos de existência ${ }^{31}$. No que tange ao ensino da disciplina Canto Coral, Maria Artiaga ${ }^{32}$ sublinha que durante o período do Estado Novo (1932 a 1975), essa modalidade de ensino esteve atrelada aos

25 Arruda, Y. Q.: Elementos do canto orfeônico, 34 4d., São Paulo, Companhia Editora Nacional, ig6o; Barreto, C. B.: Coro Orfeão, São Paulo, Companhia Melhoramentos, 1938.

${ }_{26}$ Gilioli, R. S. P.: «Civilizando» pela música: a pedagogia do canto orfeônico na escola paulista da primeira república (I9Io-1930), São Paulo, Universidade de São Paulo, Faculdade de Educação, 2003 .

Barreto, C. B.: Coro Orfeão, São Paulo, Companhia Melhoramentos, I938.

28 Almeida, J. M.: Aulas de canto orfeônico para as quatro séries do curso ginasial, São Paulo, Nacional [s. d.].

${ }_{29}$ Aruda, Y. Q.: Elementos do canto orfeônico, 34 4d., São Paulo, Companhia Editora Nacional, ig6o.

30 Santos, E. S.; Ferronato, C. J. e Mecemas. A. L.: «Nos tornos da officina do povir: o Hinário Escolar Sergipano à luz da cultura material escolar», in Monti, E. M. G. e RochA, I. A.: «Ecos e memórias: histórias de ensinos, aprendizagens e música», Teresina, EDUFPI, 2019, pp. I27-152.

${ }_{31}$ Bonito, R.: Canto coral e vida orfeônica: subsídio para a bistória do canto colectivo popular e artístico, Porto, Alttiormelior, 1952.

32 Artiaga, M. J.: «A disciplina de Canto Coral e o seu Repertório de 1918 a 1960», Revista Música, Psicologia e Educação, Centro de Investigação em Psicologia da Música e Educação MusicalCIPEM, Porto, Escola Superior de Educação do Porto (20or). 
EDUCAÇÃO MUSICAL ESCOLAR EM PORTUGAL:

364 A DISCIPLINA CANTO CORAL NA PRIMEIRA REPÚBLICA (I9IO-I926)

ELIAS SOUZA DOS SANTOS ; MARGARIDA LOURO FELGUEIRAS Y CRISTIANO FERRONATO

interesses da ideologia desse regime, que apoiou o ensino do Canto Coral, não vislumbrando o aspecto da formação integral, que ela podia trazer ao escolar, mas porque percebeu o quanto a mesma seria útil para controlar, disciplinar e incutir a ideologia desse sistema político.

\section{O Canto Coral na Escola Primária Portuguesa (1878-1909)}

Convêm recuar um pouco o marco temporal desta investigação, a fim de situar melhor as primeiras tentativas da inclusão da disciplina Canto Coral no currículo da escola portuguesa. Foi na Reforma de Ensino de I878 que a referida matéria passou a fazer parte do currículo da escola primária, antes mesmo da proclamação da República. Durante o período de I878 a I9I8 foram publicados diversos manuais escolares, destinados ao ensino da teoria musical, do solfejo e da prática do Canto Coral. Apesar de não se constituir uma tradição no currículo da escola do século xix, conforme nos informa Viana ${ }^{33}$, a disciplina Canto Coral já estava inserida no currículo da escola primária, sendo amparada pela legislação e a sua prática foi orientada pelos manuais do ensino da música, publicados no mesmo período.

Para termos uma noção da publicação de manuais escolares anterior ao ano de I9I8, achamos oportuno listar os nomes dos manuais de Canto Coral e seus respectivos autores: I. José Pereira Leite de $\mathrm{Neto}^{34}$. Noções elementares de música. Vale ressaltar que esse manual foi publicado cinco anos antes da disciplina Canto Coral fazer parte do currículo da escola primária. Isto nos leva a afirmar que já existia profissionais docentes preocupados em transmitir um ensino da educação musical ao público infantil; 2. Eduardo Macedo ${ }^{35}$. Princípios elementares de música: para uso das escolas de ensino primário de um a outro sexo: collidos segundo o programa official; 3. J. T. da Silva Bastos ${ }^{36}$. Noções de Música. Este manual foi publicado no Rio de Janeiro, mas, provavelmente, deve ter circulado nas escolas portuguesas porque a editora, sediada em Lisboa, mantinha uma filial no Brasil e na capa aparece a expressão: «Propaganda de Instrução para Portugueses e Brasileiros»; 4. César das Neves ${ }^{37}$. Escola primária de canto coral: para o ensino de música a crianças de ambos os sexos em Collegios, Lyceus, Seminários e outras escolas conforme o programa oficial; 5 . César das $\mathrm{Neves}^{38}$. Compêndio de música:

33 Viana, L.: A mocidade portuguesa: Lá vamos cantando... (1936-1974), Lisboa, Educa, $200 \mathrm{I}$.

34 Neto, J. P. L. N. Noções elementares de música, Propriedade do Editor Custódio Cardoso Pereira, Porto, Typographia Occidental, I882.

35 Macedo, E.: Princípios elementares de música: para uso das escolas de ensino primário de um e outro sexo: colligidios segundo o programa official, 2. ${ }^{\text {a }}$ ed., Porto, Livraria Portuense de Lopes, 1886.

${ }_{36}$ Bastos, J. T. S.: Noções de Música. $3 .{ }^{a}$ ed., n. ${ }^{\circ}$ 26, Rio de Janeiro, Devid Corazzi, i887.

37 Neves, C.: Escola primária de canto coral: para o ensino de música a crianças de ambos os sexos em Collegios, Lyceus, Seminários e outras escolas conforme o programa oficial, Porto, Livraria Portuense de Lopes, I89I.

${ }_{38}$ Neves, C.: Compêndio de música: solfejo e canto coral para alunos de ambos os sexos das Escolas Normaes, Lyceus, Seminários e Collegios, etc. Conforme o programa oficial, Porto, Livraria Portuense de Lopes, 1902. 
EDUCAÇÃO MUSICAL ESCOLAR EM PORTUGAL:

A DISCIPLINA CANTO CORAL NA PRIMEIRA REPÚBLICA (I9IO-I926)

ELIAS SOUZA DOS SANTOS ; MARGARIDA LOURO FELGUEIRAS Y CRISTIANO FERRONATO

solfejo e canto coral para alunos de ambos os sexos das Escolas Normaes, Lyceus, Seminários e Collegios, etc. Conforme o programa oficial; 6. Bernardo. V. Moreira de $\mathrm{Sa}^{39}$. Compêndio de música: em rigorosa concordância com o programa das Escolas Normais e de habilitação para o magistério primário e aprovado pela comissão técnica permanente.

Os referidos manuais escolares, publicados antes da Proclamação da República, apresentam uma metodologia quase semelhante. Alguns exploram apenas o solfejo, enquanto os demais apresentam, primeiramente, os conteúdos elementares da teoria musical, seguindo-se as canções de canto coral. As letras das canções apresentadas na maioria desses manuais valorizam a natureza, as árvores, as aves, o homem do camponês; outras apresentam um caráter de religiosidade e da beleza do campo. Nesses manuais o caráter nacionalista não é observado com tanta ênfase, embora apareçam algumas músicas, cujos títulos têm relação direta com Portugal, por exemplo, Amor a Portugal. Contudo, não se percebe, no discurso inerente às letras das canções, uma evidência forte ao patriotismo ou civismo.

Um dado importante, que chamou a nossa atenção, foi o fato de no compêndio de autoria de Bernardo de Sá [s. d.] - provavelmente publicado nos primeiros anos do século $\mathrm{xx}$ - apresentar, a partir da lição de n. ${ }^{\circ}$ 8, exercícios musicais com base em temas de música do cancioneiro popular de vários países: Música popular flamenga; Música popular francesa; Canção alemã; Cantiga portuguesa; Canção norueguesa; Canção austríaca; Canção sueca; Canção irlandesa; Melodia de Mozart (I756-179I); Canção russa; Melodia de Haydn (I732-1809); Canção nacional hollandeza (século xvi); Hymno inglês; Canção popular escocesa. O referido compêndio não contemplou músicas somente do cancioneiro português, ao contrário, apresentou uma séria de músicas de outros países. Portanto, observa-se que não existia uma ideologia de patriotismo nacionalista fechada, e um civismo de caráter localista impregnados nos manuais escolares de canto coral desse período. Esta abertura à cultura européia tanto pode ser interpretada como representando uma visão integradora ou como uma manifestação de crise de identidade da cultura portuguesa da época. Vale ressaltar, que ambos os sentimentos estivessem presentes, dada a tradicional abertura portuguesa ao exterior e, simultaneamente, o sentimento de decadência que marcou os intelectuais portugueses do final do século xIx. A pouca atenção à produção cultural nacional teria como correlato a subordinação a cânones musicais externos e, mesmo, um sentimento de inferioridade face às possibilidades musicais da própria língua.

39 SÁ, B. V. M.: Compêndio de música: em rigorosa concordância com o programa das Escolas Normais e de habilitação para o magistério primário e aprovado pela comissão técnica permanente, $7 .^{a}$ ed., muito ampliada com um dicionário musical e biográfico, Porto, Editora Casa Moreira de Sá, [s. d.]. 
EDUCAÇÃO MUSICAL ESCOLAR EM PORTUGAL:

366 A DISCIPLINA CANTO CORAL NA PRIMEIRA REPÚBLICA (I9I0-I926)

ELIAS SOUZA DOS SANTOS ; MARGARIDA LOURO FELGUEIRAS Y CRISTIANO FERRONATO

\section{O Canto Coral na Escola da Primeira República (I810-1926)}

Ao discutir o conceito de disciplina, André Chervel destaca que a palavra apareceu tardiamente no ensino secundário. A ideia era formar os espíritos mediante os treinos do pensamento intelectual. Segundo o autor,

A razão desse atraso é simples. Até I880, mesmo até I902, para a Universidade não há senão um modo de formar os espíritos, não mais do que uma «disciplina», no sentido forte do termo: as humanidades clássicas. Uma educação que fosse fundamentalmente matemática ou científica não deveria ser, antes do século xx, plenamente reconhecida como uma verdadeira formação do espírito. É somente quando a evolução da sociedade e dos espíritos permite contrapor à disciplina literária a uma disciplina científica que se faz sentir a necessidade de um termo genérico ${ }^{40}$.

De acordo com o autor francês, o termo disciplina, sobretudo depois da I Guerra Mundial, adquire um caráter linguístico diferente do anterior, e se refere ao nome que classifica as matérias de ensino e tem apenas uma ligação remota com o conceito de formação do espírito. A disciplina Canto Coral, inserida no currículo da escola no final do século XIx, aos poucos vai ganhando visibilidade. Oito anos depois da instauração do Período Republicano, por meio do Decreto n. ${ }^{\circ} 4650$ de I4 de Julho de 1918, o Canto Coral passa a fazer parte dos currículos, tanto no currículo da escola primária quanto nos cinco anos do curso geral dos Liceus. Para entendermos com mais propriedade o modo como essa disciplina se estabeleceu no currículo, vamos observar o que Luís Viana nos diz:

Diploma do consulado de Sidónio Pais consagrava o ensino da disciplina nos cinco anos do curso geral (duas horas nos dois primeiros anos e uma nos três seguintes) e estabelecia que este deveria contribuir não só para a educação da voz e do sentimento mas ainda para o desenvolvimento do espírito nacionalista $\left(\operatorname{art}^{\circ}{ }_{20}^{\circ}\right)^{41}$.

Para o historiador português Raimundo Pintassilgo, o período republicano, em Portugal, foi pautado pelos temas voltados à modernização da educação, à racionalização do ensino, da alimentação, da higiene e da saúde do escolar. As práticas pedagógicas da escola republicana procuraram evidenciar a formação dos cidadãos, com ênfase na ideologia patriótica, tendo em vista à «interiorização de uma memória colectiva que servisse de base ao fortalecimento da identidade nacional $\gg^{42}$. Nesse caso, a disciplina Canto Coral, ao lado da educação moral e cívica contribuíram para a inculcação de preceitos, a exemplo da formação do

${ }^{40}$ Chervel, A.: «História das disciplinas escolares: reflexões sobre um campo de pesquisa», Teoria E Educação, n. 2 (1990), pp. 179-180.

${ }_{41}$ Viana, L.: A mocidade portuguesa: Lá vamos cantando... (1936-I974), Lisboa, Educa, 200I, p. 66.

${ }_{42}$ Pintassilgo, J.: A República e a Educação: dos projectos às realizações, Biblioteca da Faculdade de Lisboa, 2oII, p. Io, https://repositorio.ul.pt/handle/IO45I/7792. 
caráter, à aquisição de hábitos disciplinares, à regeneração física do povo português e à efetivação do espirito ufanista, ou seja, patriótico.

A luta pela inserção de uma disciplina no currículo da escola, normalmente parte dos profissionais da área e de grupos de interesse localizados na socieda$\mathrm{de}^{43}$; neste caso, os professores de música. Antes de uma disciplina ser inserida no currículo mediante a publicação de um decreto, ocorre um movimento de luta e tensão entre os profissionais e os políticos (governo). No caso da disciplina Canto Coral, sua análise está sendo respaldada pelos trabalhos de Luiz Viana e Maria Artiaga, pesquisador/a português/sa, que produziram estudos sobre a referida disciplina. Além desses trabalhos, tomamos como fontes os próprios manuais escolares de Canto Coral produzidos no período da Primeira República (i9ro a I926).

No dizer de Artiaga, há uma semelhança dos objetivos da disciplina Canto Coral com os apresentados nos

[...] manuais do Padre Tomás Borba, excepto no que respeita às canções nacionalistas quase inexistentes nos seus livros. O regulamento determina três critérios a que devia obedecer o Canto Coral: o da 'moral', da 'beleza' e o do «sentimento nacionalista», devendo-se excluir as canções que pudessem «suscitar a imoralidade» e as que não concorressem «para educar artisticamente o aluno» ${ }^{44}$.

As potencialidades formativas da música, sobretudo no Canto Coral, aliamse, no início do século $\mathrm{xx}$, com questões que estavam sendo discutidas naquele momento: a higiene e o desenvolvimento intelectual. Dessa forma, o Canto Coral, enquanto disciplina, traria quatro vantagens para o desenvolvimento do escolar: formação moral, higiênica, intelectual e disciplinar. Portanto, «os exercícios de canto robusteceriam o aparelho respiratório ao tempo que desenvolveriam no aluno capacidades de atenção e sentimentos de obediência» ${ }^{45}$.

Conforme as elucidações de Viana, apesar da disciplina ter recebido essa atenção, mormente, no que se refere aos benefícios que traz para a formação da personalidade do escolar, posteriormente veio a perder sua autonomia, pois, de acordo com a autora, o Decreto n. ${ }^{\circ} 4650$ de 1918 criou a disciplina Canto Coral e instituiu a criação de um orfeão. Sendo assim, esse fato prejudicou significativamente seu processo de autonomia e desenvolvimento no período republicano, uma vez que a atenção maior foi destinada para os ensaios e apresentações dos orfeões, ficando a disciplina em segundo plano.

Outro problema agravante levantado por Viana, tem a ver com o quadro docente da disciplina. A maioria dos professores que se disponibilizavam para

${ }^{43}$ STEnhouse, L.: Investigación y desarrollo del currículum, trad. espanhola, 2. ${ }^{a}$ ed., Madrid, Morata, 1987.

44 Artiaga, M. J.: «A disciplina de Canto Coral e o seu Repertório de 1918 a 1960», Revista Música, Psicologia e Educação, Centro de Investigação em Psicologia da Música e Educação MusicalCIPEM, Porto, Escola Superior de Educação do Porto (20or), p. 43.

45 Viana, L.: A mocidade portuguesa: Lá vamos cantando... (1936-1974), Lisboa, Educa, 200I, p. 67. 
o ensino do Canto Coral não tinha formação na área. Essa falta de qualificação docente e outros problemas pertinentes à disciplina levou o governo a publicar uma série de Decretos que tinham como finalidade instituir, de forma eficaz, a disciplina. Observarmos os decretos que foram publicados no período de I9I8 a I930, considerado por Viana como sendo o primeiro momento de legalização do Canto Coral. Além do decreto que cria a disciplina, seguiram-se outros, que enumeramos e que ultrapassam, já, o período da I. ${ }^{a}$ República: Decreto n. ${ }^{\circ} 8808$ de 9 de Maio de 1923, que exclui o voluntariado para a disciplina; Decreto n. ${ }^{\circ}$ I2425, de 2 de Outubro de 1926, que cria o lugar de professor efetivo de Canto Coral no quadro dos Liceus (regente efectivo); Decreto n. ${ }^{\circ}$ 13571, de 9 de Maio de 1927, que exige, dos professores candidatos ao ensino do Canto Coral, o curso de formação em música; Decreto n. ${ }^{\circ}$ I4310 de 22 de Setembro de 1927, que estabelece normas para o provimentos das vagas, dando-se preferência para professores formados pelo Conservatório Nacional de Música; Decreto n. ${ }^{\circ}$ I50I9 de in de Fevereiro de 1928, que estabelece os vencimentos do quadro docente; Decreto n. ${ }^{\circ}$ i8779 de 26 de Agosto de 1930, que confirma a disciplina no currículo dos Liceus; Decreto n. ${ }^{\circ}$ I8885 de 27 de Setembro de 1930, que apresenta o estatuto do Canto Coral nos referidos contextos. Percebe-se que, através do mecanismo legal a disciplina foi introduzida e mantida no sistema de ensino, uma vez que ele era centralizado e toda a alteração curricular passava pela aprovação ministerial e publicação em lei. A diferença notória que estes decretos patenteiam é a passagem da disciplina, do âmbito do ensino primário obrigatório, para se configurar como uma disciplina no quadro da educação secundária e de elite - o ensino liceal. A ênfase do Canto Coral, no ensino primário, desaparece, ficando apenas a obrigatoriedade de se aprender e cantar o Hino Nacional. Contudo, é oportuno atentarmos para a crítica que Viana faz sobre o período da Ditadura Nacional:

Em suma, tratava-se de manter a disciplina sem lhe definir um conteúdo concreto e sem lhe alargar os horizontes. Sem programa expresso, sujeito apenas à orientação vaga do visar o «desenvolvimento de sentimentos nacionalistas», somos levados a crer que a sua aplicação prática se terá revestido de uma heterogeneidade mais do que natural e ao sabor das predileções de professores e reitores. Comum, por certo, teremos apenas o ensino do Hino Nacional (ainda que seu canto diferisse de liceu para liceu-Cf. MP, 1962, Diretrizes para o Canto Coral..., p. Io $)^{46}$.

Mesmo com os esforços de alguns profissionais da área, sobretudo dos autores de manuais escolares para fazerem valer a funcionalidade das práticas da disciplina Canto Coral, observamos que nem no período republicano, apesar da importância social que lhe era atribuída, nem durante a Ditadura, que teve o apoio da legislação, a disciplina conseguiu ocupar um lugar de destaque no currículo escolar. p. 68.

Viana, L.: A mocidade portuguesa: Lá vamos cantando... (1936-1974), Lisboa, Educa, 200I, 
EDUCAÇÃO MUSICAL ESCOLAR EM PORTUGAL:

A DISCIPLINA CANTO CORAL NA PRIMEIRA REPÚBLICA (I9IO-I926)

ELIAS SOUZA DOS SANTOS ; MARGARIDA LOURO FELGUEIRAS Y CRISTIANO FERRONATO

\section{Os manuais escolares de Canto Coral (1910-1926)}

Durante o período de I9Io a 1926 registramos a publicação de alguns manuais escolares. $\mathrm{Na}$ verdade, eles refletem a mentalidade dos autores sobre o modo de transmitir os conteúdos da disciplina. Porém, tal como afirma Chervel ${ }^{47}$, devem ser lidos no contexto de toda uma produção de escritos sobre a escola e sobre a rede de dependências funcionais, hierárquicas e sociais, para podemos encontrar a «chave», no sentido de compreendermos as práticas e do que os mestres consideravam o contributo da disciplina para a formação dos alunos e alunas.

Identificamos apenas quatro manuais escolares publicados no período republicano. É provável que um número maior tenha sido produzido, entretanto optamos por elencar apenas os que trazem impressos o ano de sua publicação.

O manual intitulado Curso elementar de canto coral: a música na escola primária, de Ernesto Vieira ${ }^{48}$, é composto por três partes: na primeira (I. ${ }^{\circ}$ caderno) o autor apresenta algumas noções elementares de teoria musical. É provável que tenha sido um livro escolar destinado ao educando e que foi produzido com certo cuidado didático-metodológico. Percebemos que o autor detinha muitos conhecimentos sobre a didática do ensino de música e de canto coral para crianças da escola primária. Contudo, mesmo sendo produzido no período inicial da República, no qual seria de esperar uma afirmação do novo regime e uma certa exaltação de sentimentos nacionalistas. que estiveram na base do republicanismo, não encontramos canções de caráter nacionalista e folclórica. Pintassilgo palavras de Pintassilgo postula que «[...] a República não representa, a não ser do ponto de vista retórico, um corte total com o passado. Algumas das tendências que vêm de trás serão prosseguidas e combinadas com aspectos de uma cultura escolar especificamente republicana e laica» ${ }^{49}$. Por outro lado, para Magalhães ${ }^{50}$, o período republicano se constituiu em um regime de educabilidade, tendo em vista às ações empreendidas pelo governo, na implementação de princípios de inovação pedagógica, que adotou o método intuitivo, como base das reformas educativas.

As reformas educativas republicanas, em Portugal, foi pautada, de acordo com Proenç ${ }^{51}$ (1997, p. 256), pela centralização educativa e pelo controle pedagógico, através da criação de currículos, dos programas, dos manuais, das metodologias

47 Chervel, A.: «História das disciplinas escolares: reflexões sobre um campo de pesquisa», Teoria E Educação, n. 2 (1990), pp. 177-229.

${ }_{48}$ Vieira, E.: Curso elementar de canto coral: a música na escola primária, Lisboa, A. M. Texeira, 1913.

49 Pintassilgo, J.: A República e a Educação: dos projectos às realizações, Biblioteca da Faculdade de Lisboa, 20II, p. 2, https://repositorio.ul.pt/handle/I045I/7792.

so Magalhães, J.: «República e Regimento Escolar: o Estatuto Fundante da Primeira Reforma Republicana do Ensino Primário», in Adão, Á.; Silva, M. e Pintassilgo, J. (orgs.): O homem vale, sobreturo, pela educação que possui: revisitando a primeire reforma republicana do ensino infantil, primário e normal, Portugal, Ministério da Educação. Fundação para a Ciência e a Tecnologia, 2oII, pp. II-2I.

sI Proença, M. C.: Reforma de Jaime Moniz: antecedentes e destino histórico, Lisboa, Colibri, 1997, p. 256. 
EDUCAÇÃO MUSICAL ESCOLAR EM PORTUGAL:

370 A DISCIPLINA CANTO CORAL NA PRIMEIRA REPÚBLICA (I9IO-I926)

ELIAS SOUZA DOS SANTOS ; MARGARIDA LOURO FELGUEIRAS Y CRISTIANO FERRONATO

de ensino, como também, no domínio administrativo, mediante a nomeação de docentes, da administração escolar, etc. Nesse tempo, tanto Jorge do $\mathrm{O}^{52}$ como Pintassilgo ${ }^{53}$, ao retratarem o período da I República, em Portugal, destacam que a prática do Canto Coral, esteve representada nos currículos dos liceus (música vocal e instrumental) e da escola primária.

Tomás Borbas ${ }^{54}$ publicou dois manuais. O primeiro intitula-se $O$ canto coral nas escolas. O segundo denomina-se Arte na escola: o canto coral nas escolas. A maioria das letras das canções contidas nesses manuais revelam aspectos da natureza, em geral, e da vida no campo. Percebe-se a ausência das músicas cívicas e pátrias. Vale atentarmos para a elucidação de Artiaga, quando analisou o manual do Padre Tomás Borba. Para a autora, tais manuais, «mantêm o mesmo tipo de temática campestre. [...] A descrição dos elementos naturais tinha objectivos éticos muitos explícitos como, por exemplo, encorajar os sentimentos humanos mais puros, ou chamar a atenção para todo o bem que vem da terra» ${ }^{55}$.

Bernardo Valentim Moreira de Sá ${ }^{56}$ publicou o Compêndio de música: em rigorosa concordância com o programa das escolas normais e de habilitação para o magistério primário. Este compêndio apresenta, logo no início, um conteúdo elementar de teoria musical destinado à r. ${ }^{a}$ classe, acrescido de lições de solfejos, produzidas conforme o nível elementar de teoria musical. Para a $2 .^{a}$ classe, aprofundam-se os conteúdos de teoria musical e aproveitam-se os exercícios de solfejo. As lições de solfejo da $3 .^{a}$ classe são as mesmas dos anos anteriores, acrescidas de um conteúdo teórico mais complexo. $\mathrm{Na}$ penúltima parte, o livro apresenta um dicionário onde constam alguns nomes relacionados com o sistema musical e nomes de musicistas. Por fim, são expostas as lições de solfejo das três classes, com 46 cantos escolares de diferentes nacionalidades, organizados em forma de arranjos corais.

Ressaltamos a presença de várias músicas de países estrangeiros nestes manuais. Acreditamos que este fato tem relação direta com o problema de identidade na história da música portuguesa, apontado por Brito e Cymbron ${ }^{57}$. Segundo esses estudiosos, no século xvi a música portuguesa foi influenciada pela Espanha, e no século xviII predominou em Portugal a música italiana: tanto a religiosa quan-

s2 Ramos do Ó, J.: O ensino liceal (1836-1975), 2009, https://repositorio.ul.pt/bitstream/I045I/6296/I/Ensino \% 20Liceal\% 20.pdf.

53 Pintassilgo, J.: A República e a Educação: dos projectos às realizações, Biblioteca da Faculdade de Lisboa, 20II, https://repositorio.ul.pt/handle/IO45I/7792.

54 Bordas, T.: O canto coral nas escolas, vol. I, Lisboa, G. de Lacerda, I913; Borbas, T.: Arte na escola: o canto coral nas escolas, Lisboa, Edição da Sociedade de Estudos Pedagógicos, I916.

"Artiaga, M. J.: «A disciplina de Canto Coral e o seu Repertório de I9I8 a I960», Revista Música, Psicologia e Educação, Centro de Investigação em Psicologia da Música e Educação MusicalCIPEM, Porto, Escola Superior de Educação do Porto (200I), p. 46.

56 SÁ, B. V. M.: Compêndio de música: em rigorosa concordância com o programa das escolas normais e de habilitação para o magistério primário, $5 .^{a}$ ed., muito aumentada, Porto, Casa Moreira de Sá, Impresso com um dicionário musical e biográfico, I9I8.

57 Brito, M. C. e Cymbron, L.: História da música portuguesa, Lisboa, Universidade Aberta, 1992. 
EDUCAÇÃO MUSICAL ESCOLAR EM PORTUGAL:

A DISCIPLINA CANTO CORAL NA PRIMEIRA REPÚBLICA (I9IO-I926)

ELIAS SOUZA DOS SANTOS ; MARGARIDA LOURO FELGUEIRAS Y CRISTIANO FERRONATO

to a operística. Já as óperas francesa e alemã foram introduzidas no meio musical português a partir das últimas décadas do século XIX. Essa influência estrangeira pode ser observada nos manuais escolares de Canto Coral publicados no final da segunda metade do século XIX e início do século Xx. Mesmo com a instauração da I República, os manuais não apresentaram músicas de caráter nacional. O caráter nacionalista começou a fazer parte dos manuais escolares e pedagógicos da disciplina Canto Coral, somente com a instituição do Estado Novo (1933), como, aliás, de todo o ensino, tendo sido dado destaque à música nacional e a popular.

\section{Considerações finais}

Inseridas no contexto da escola, as disciplinas escolares seguem um curso histórico paralelo aos acontecimentos políticos e sociais. Quando pretende se debruçar sobre a trajetória de uma disciplina, o investigador encontra-se em face de outras linhas de pesquisas que têm como objeto de estudo outros aspectos da cultura escolar. Ao traçar a trajetória de uma disciplina, automaticamente nos vemos obrigados a examinar várias fontes que são comuns a outras áreas e que estão interligadas: legislação escolar, história da profissão docente, história dos manuais escolares e pedagógicos e a história dos currículos. Na verdade, as práticas desenvolvidas no interior de cada disciplina, como afirma Julia ${ }^{58}$, são a "caixa preta» da escola. Nelas se encontram parte dos segredos geradores das culturas escolares.

No século XIX a Europa investe na prática orfeônica como elemento integrador, difundindo-a não somente nas escolas, mas também em toda a sociedade. As associações orfeônicas disseminaram-se por vários países da Europa e da América do Norte e do Sul. O movimento surtia um efeito de harmonização e integração social e era utilizado como forma de despertar sentimentos de adesão e amor aos símbolos pátrios do país. Portugal não ficou atrás. Nesse mesmo século surge o Orfeão Acadêmico de Coimbra e no início do século xx é criado o Orfeão do Porto. A disciplina Canto Coral aparece no currículo da escola primária na segunda metade do século xIx e no século seguinte, com a instauração da República, passou a fazer parte do currículo dos Liceus. Nesse tempo os professores publicaram manuais escolares que deram orientações para as práticas da disciplina. Tais manuais são fontes preciosas para se perceber os mecanismos de instituição e de transmissão do saber musical.

$\mathrm{Na}$ I República, a disciplina Canto Coral aparece, ainda de forma tímida, no currículo. Vai ganhar espaço com as novas orientações da Ditadura, que se traduzem na profusa publicação de decretos. Quanto aos manuais escolares, percebemos que o caráter das canções estava distante de uma ideologia nacionalista estrita, ou seja, os autores davam prioridade às músicas, cujas letras retratavam a

58 Julia, D.: «A cultura escolar como objeto histórico», Revista Brasileira de História da Educação, Campinas, Editora Autores Associados, n. ${ }^{\circ}$ I (Jan./Jun., 200I), pp. 9-43. 
natureza, os animais e a vida campestre. Buscava-se, sobretudo, o efeito de harmonia e beleza. O nacionalismo apenas se manifestava no canto da Portuguesa (Hino Nacional de Portugal), como símbolo e apelo à luta pela defesa da Pátria. Somente a partir de 1933, com a instauração do Estado Novo, o Canto Coral assume uma nova configuração no contexto escolar e social. Nesse tempo, o nacional e o popular vão ser convocados para os novos manuais escolares publicados, fossem eles de música ou de outra matéria.

O tempo da permanência da disciplina Canto Coral na I República foi efêmero, mas pode-se considerar esse período frutífero, sobretudo em nível da legislação. Foi o momento de instituição de um campo disciplinar, originado não na universidade, mas no interior da escola, na sua relação com as dinâmicas sociais. A música deixa de ser um saber apenas desenvolvido pelos conservatórios, para profissionais, ou na esfera privada, para amadores. É o momento da pedagogização do saber musical, que passou a ser transmitido nos diversos níveis de ensino, sem o propósito de formar o músico profissional, mas, sobretudo, para formar a personalidade e disciplinar os hábitos dos escolares.

O tempo disponível para desenvolvermos este trabalho não foi suficiente para perseguirmos a trajetória dos profissionais docentes, autores dos manuais escolares. Contudo, achamos que este estudo é importante para compreendermos os modos pelos quais se concebe ou se institui, no interior da escola, um campo disciplinar. 